\title{
Impact of residues of veterinary medicinal products in food of animal origin on public health safety in Poland in the years 2003-2017
}

\author{
MICHAŁ MAJEWSKI, KRZYSZTOF ANUSZ*, ZBIGNIEW BEŁKOT**, \\ PRZEMYS $\longleftarrow A W$ RACEWICZ, ANNA ŁUKOMSKA***
}

\begin{abstract}
Division of Veterinary Public Health Protection, ***Department of Preclinical Sciences and Infectious Diseases, Faculty of Veterinary Medicine and Animal Science, University of Life Sciences in Poznań, ul. Słoneczna 1, 62-002 Złotniki

*Department of Food Hygiene and Public Health Protection, Institute of Veterinary Medicine,

Warsaw University of Life Sciences (WULS-SGGW), Nowoursynowska 159, 02-776 Warsaw

**Department of Food Hygiene of Animal Origin, Faculty of Veterinary Medicine, University of Life Sciences in Lublin, ul. Akademicka 12, 20-033 Lublin
\end{abstract}

Majewski M., Anusz K., Bełkot Z., Racewicz P., Łukomska A.

Impact of residues of veterinary medicinal products in food of animal origin on public health safety in Poland in the years 2003-2017

\section{Summary}

Monitoring the presence of residues of unauthorized substances, chemical and biological residues, medicinal products and radioactive contamination in food is an important element of the system for protection of consumers against hazardous foods. The aim of the study was to analyze the results of monitoring tests for the presence of antibiotics and chemotherapeutics affecting consumer safety in products of animal origin that were carried out in Poland in the years 2003-2017. The material for analysis were annual reports on the results of tests for the presence of prohibited substances, chemical and biological residues, medicinal products and radioactive contamination in food produced in Poland. Samples for testing were taken at random from food of animal origin produced on farms under the supervision of the Veterinary Inspectorate. The reports present data on monitoring tests carried out in the years 2003-2017. The analysis was based on the results for B1 substances, which include antibacterial substances, antibiotics and chemotherapeutics approved for use in food-producing animals. The results from the last two years of research were analyzed in detail, including the results for prohibited substances with antibacterial action from group A6 (prohibited substances) and, in the case of poultry, for coccidiostats (group B2b).The results of the monitoring studies in Poland indicate that both veterinarians and animal breeders were aware that the proper use of chemotherapeutics and compliance with waiting periods are necessary to ensure food safety. Samples that exceeded the standards represented less than $0.3 \%$ of all samples tested in all types of food. According to the results of these studies, antibiotic residues were most frequently found in honey.

Keywords: residues, food safety, food of animal origin, food inspection

The intensification of production makes bacterial infectious diseases a serious problem for livestock farmers all over the world. Constantly increasing productivity and stocking densities in livestock buildings make it difficult to maintain welfare, which increases the infection risk. In addition, high animal productivity also increases susceptibility to disease. In consequence, there is a growing use of antibiotics.

Food safety is one of key issues in effective public health protection. The use of veterinary medicinal products in animals poses a potential risk of residues in food, which may be a threat to the consumers' health (1). Due to the prevalence of medicinal products, all types of food of animal origin, especially meat and milk, are at risk of contamination.

The need for continuous risk monitoring associated with the presence of unauthorized substances, chemical and biological residues, medicinal products and radioactive contaminants in food is pointed out in Council Directive 96/23/EC of 1996 (3). Subsequent legislation on food production has harmonized the way in which it is handled and introduced the requirement 
to collect data on the residue situation in all countries of the European Union (EU) (17). The provision that implements the requirements of the Council Directive in Poland is the Regulation of the Minister of Agriculture and Rural Development of 21 June 2017 on monitoring prohibited substances, chemical and biological residues, medicinal products and radioactive contaminants (21). This integrated approach makes it possible to ensure standardized high-level consumer protection throughout the EU.

Since antibiotics and chemotherapeutic agents (including veterinary medicinal products) are authorized for use in food-producing animals, it was necessary to determine maximum residue limits for medicines in tissues intended for human consumption, as described in Regulation (EC) No 470/2009 of the European Parliament and of the Council (18). Maximum residue limits for medicines in various types of food are stated in Commission Regulation (EU) No 37/2010 on pharmacologically active substances and their classification regarding maximum residue limits in foodstuffs of animal origin (2).

The legal grounds for implementation of Council Directive 96/23/EC of 29 April 1996 in Poland was the Regulation of the Minister of Agriculture and Rural Development of 20 March 2003 on control tests of chemical and biological residues, medicines and radioactive contaminants in live animals, in tissues or organs of animals after slaughter and in food products of animal origin, repealed by the regulations of 2004 and $2006(3,19,20,22)$. The Regulation of the Minister of Agriculture and Rural Development of 21 June 2017 on the monitoring of prohibited substances, chemical and biological residues, medicinal products and radioactive contamination (Journal of Laws from 2017, item 1246) is currently in force. It specifies, among others, the number of samples that have to be tested in each category (Tab. 1) (21).

The true scale of risks associated with residues of veterinary medicinal products is difficult to assess. Unlike infectious agents that may be present in food,

Tab. 1. Percentage of animals slaughtered or the number of samples that have to be tested for B1 substances (antibiotics, chemotherapeu tics, antibacterial substances

\begin{tabular}{|l|c|}
\hline $\begin{array}{c}\text { Products } \\
\text { of animal origin }\end{array}$ & $\begin{array}{c}\text { Percentage of animals slaughtered } \\
\text { or the number of samples that have to be tested }\end{array}$ \\
\hline Cattle & $0.4 \%$ \\
Swine & $0.05 \%$ \\
Sheep \& goats & $0.05 \%$ \\
Equids & min. 100 animals \\
\hline Poultry & 1 sample/200 t $\mathbf{0 . 0 5 \% )}$ \\
Fish & 1 sample/100 t \\
\hline Milk & 1 sample/15 000 t \\
Eggs & 1 sample/10 000 t \\
Honey & 10 samples/300 t \\
\hline
\end{tabular}

chemicals rarely cause immediate adverse health effects.

It is estimated that $80 \%$ of food-producing animals undergo antibiotic therapy at least once in their lifetime (12). This means that a rational use of medicinal products is of profound importance for public health protection. Thanks to the knowledge of pharmacokinetics and pharmacodynamics of medicines, it is possible to precisely determine the withdrawal period (the time necessary to eliminate residues of pharmacologically active substances from tissues obtained for human consumption after the end of therapy). Lack of veterinary supervision over the use of drugs in animals may lead to non-compliance with this period and the presence of drug residues in food.

Abnormal dosage and administration of drugs is equally dangerous. Residues of pharmacologically active substances may also occur in cases of crosscontamination of drinking systems or feed administration. Moreover, the rate at which drug residues are removed from the body is influenced by factors such as age, nutrition and health status.

Unconscious intake of antibiotic residues by consumers may cause adverse effects. The most important among them are allergic reactions, which may occur after consuming even small amounts of $\beta$-lactam antibiotics (27).

There are significant differences in therapeutic substances used. The most important food-producing animals are pigs, poultry and cattle. Commonly used groups of veterinary medicinal products in the EU are tetracyclines $(32 \%)$, penicillins $(26 \%)$, sulfonamides $(12 \%)$, macrolides $(7 \%)$, polymyxins $(5 \%)$ and aminoglycosides $(5 \%)(8)$.

It should be mentioned that many of the antibiotics used in veterinary medicine are also used in human medicine. Adverse reactions are reported in a small percentage of patients, and the presence of antibiotic residues at concentrations well below therapeutic doses effectively reduces the risk of such reactions. However, low concentrations of antibacterial drugs may exert a selective pressure on bacteria, leading to the proliferation of resistant strains, both in food of animal origin and in humans. Other consequences of continuous intake of antibiotics in the form of residues are disorders of intestinal flora.

The aim of the study was to analyze monitoring tests for the presence of antibiotics and chemotherapeutics affecting consumer safety in products of animal origin carried out in Poland in the years 2003-2017.

\section{Material and methods}

The material for analysis were annual reports published on the website of the Chief Veterinary Inspectorate that present the results of tests on the presence of prohibited substances, chemical and biological residues, medicinal products and radioactive contaminants in food produced in Poland. These reports present data on monitoring tests 
performed from 2003 to 2017 . The samples were collected randomly, where there was no special reason to expect the presence of the substances tested. The material examined was food of animal origin produced in farms under the supervision of the Veterinary Inspectorate. The analysis was based on the results for B1 substances, which include antibacterials, antibiotics and chemotherapeutics approved for use in food-producing animals. The results from the last two years of the study were analyzed in detail, including the results for prohibited substances with antibacterial action from group A6 (prohibited substances) and, in the case of poultry, for coccidiostats (group B2b).

Two methods were used for the determination of the residue level. For the group of ,antibacterial substances,” the 5-plate diffusion method was used according to instructions of the PIP-PIB Puławy. The currently valid instruction is the PIP-PIB Pulawy document ,Instruction for detection of residues of antibacterial substances (Group B1) by the screening microbiological method" from 2011. Tests for ,antibiotics and chemotherapeutics" were performed by liquid chromatography with tandem mass spectrometry detection. Guidance on the methodology is contained in the document „Analysis of residues of antibacterial drugs in biological material by liquid chromatography with mass spectrometry" of the PIW-PIB Puławy from 2013.

\section{Results and discussion}

Cattle. From 2003 to 2017, a total of 20,022 tissue samples from cattle were tested, and 87 non-compliant results were obtained, which is $0.43 \%$ of all tests performed (Fig. 1). Due to the regular increase in the

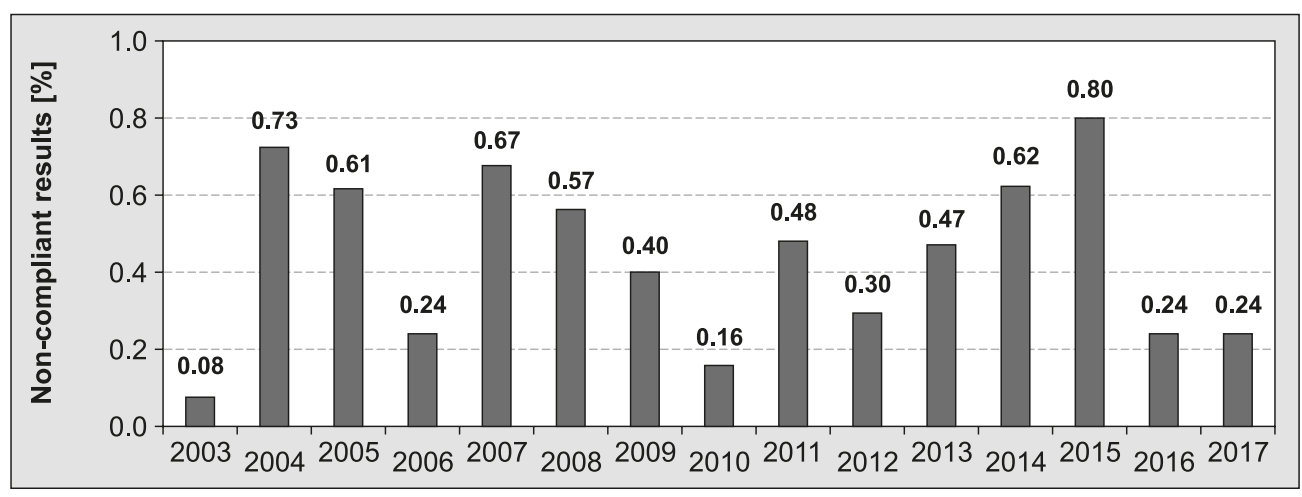

Fig.1. Percentage of results non-compliant with EU MRLs (Maximum Residue Levels) for antibiotics and chemotherapeutics in cattle from 2003 to 2017

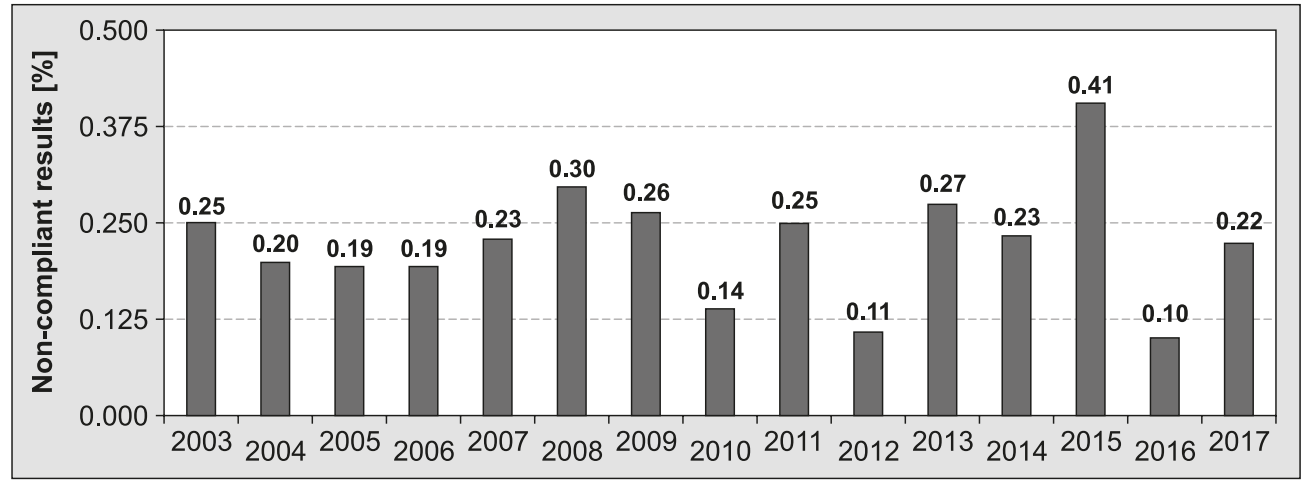

Fig. 2. Percentage of results non-compliant with EU MRLs (Maximum Residue Levels) for antibiotics and chemotherapeutics in pigs from 2003 to 2017 number of animals slaughtered, the number of samples in the last year increased proportionally by $28 \%$ compared to the number of animals tested in 2003. In 2016 and 2017, respectively, 1635 and 1641 samples of bovine tissues were examined, among which 4 results were non-compliant in both years. In 2016, a single case of oxytetracycline in muscles was found. Three kidney samples contained dihydrostreptomycin. One muscle sample contained chloramphenicol. In 2017, the results of the study were more varied. One muscle sample contained oxytetracycline, while in kidneys one sample with dihydrostreptomycin and one with oxytetracycline were found. The third sample was positive for four substances: enrofloxacin, marbofloxacin, penicillin $\mathrm{G}$ and neomycin. In addition, two muscle samples were positive for chloramphenicol, and a substance not authorized for use in food-producing animals was found in two muscle samples. Due to its classification in group A, these results were not considered in this summary. The percentage of non-compliant results obtained during 15 years of monitoring ranged from 0.08 in the first reported year of testing to 0.8 in 2015 , meaning that 1 to 12 samples per year were non-compliant.

Pigs. In the period from 2003 to 2017, a total of 54964 samples of pork meat were examined. Maximum residue levels were exceeded in 123 samples, that is, $0.22 \%$ (Fig. 2). The number of samples collected for monitoring purposes increased from 3231 in 2003 to 4018 in 2017. The percentage of non-compliant results ranged from $0.10 \%$ in 2016 and $0.11 \%$ in 2012 to $0.41 \%$ in 2015 . In 2016 , a total of 3926 samples were collected in slaughterhouses and subsequently tested for the presence of antibacterial substances (3000 samples), antibiotics and chemotherapeutic agents (896 samples), colistine, valnemulin and amphenicols (10 samples for each). The limits for antibiotics and chemotherapeutics were exceeded in 4 of those samples. Oxytetracycline and dihydrostreptomycin were found in kidneys (in 1 sample each), whereas oxytetracycline and doxycycline were detected in muscle and kidney complex (in 1 sample each). In addition, chloramphenicol was found in 2 muscle samples $(0.26 \%$ of all tissues tested for this substance). In 2017, the number of samples increased to 4018: 3052 for 
antibacterial substances, 933 for antibiotics and chemotherapeutics, 13 for colistin, and 10 for valnemulin and amphenicol. All 9 non-compliant results were found, as in the previous year, in samples tested for the presence of antibiotic and chemotherapeutic residues. Doxycycline was found in 8 samples: 6 muscle samples, 1 kidney sample and 1 muscle and kidney sample. The maximum residue limit (MRL) for enrofloxacin was exceeded in 1 muscle and kidney sample.

Poultry. Poultry is a very large and varied group of slaughter animals. The sampling rate takes account of significant differences in the number of chickens, turkeys, ducks and geese in the population. During the 15 years of the study, a total of 25022 muscle samples from poultry were tested. Chicken samples made up $85 \%$, while $11 \%$ of samples came from turkeys, $2 \%$ from ducks and $2 \%$ from geese. Data classified by species are available for the period 2005-2017. The first two annual reports present results for all bird species combined (Fig. 3). Non-compliant results are distributed disproportionately among different poultry groups. In as many as 9 years (2005-2006, 2011-2017) out of the 13 for which data by species are available, MRLs were exceeded only in samples of meat from broilers. In the years 2007, 2008 and 2009 the vast majority $(87.5 \%, 83.3 \%$ and $80 \%$ respectively) of positive samples were muscles collected from chickens. One positive result in 2008 and one in 2009 were found in tissues from turkeys. In 2007, MRL was exceeded in one duck tissue sample. In 2010, tests

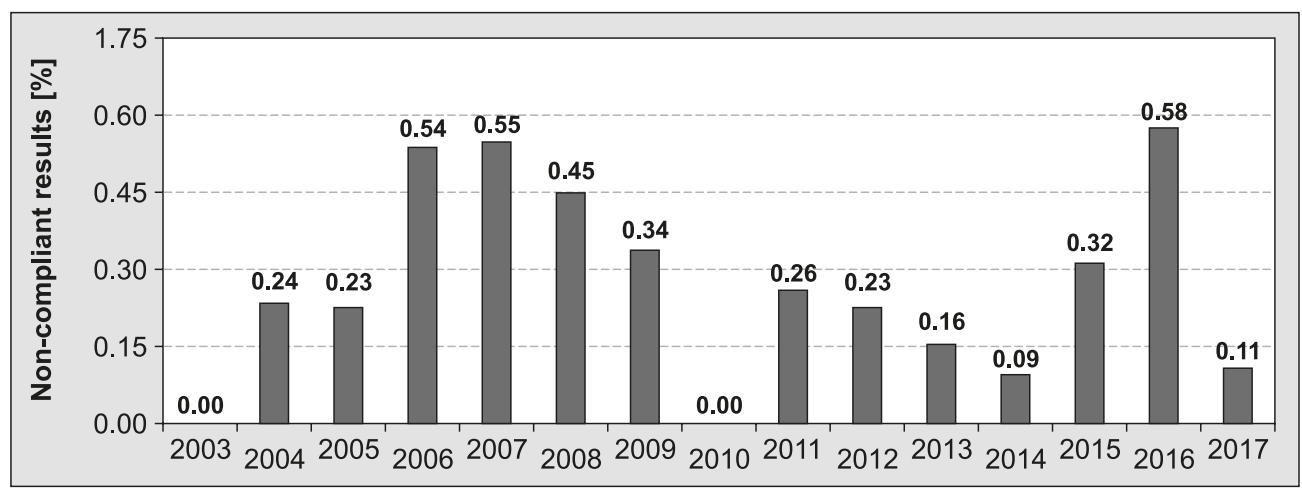

Fig. 3. Percentage of results non-compliant with EU MRLs (Maximum Residue Levels) for antibiotics and chemotherapeutics in poultry from 2003 to 2017

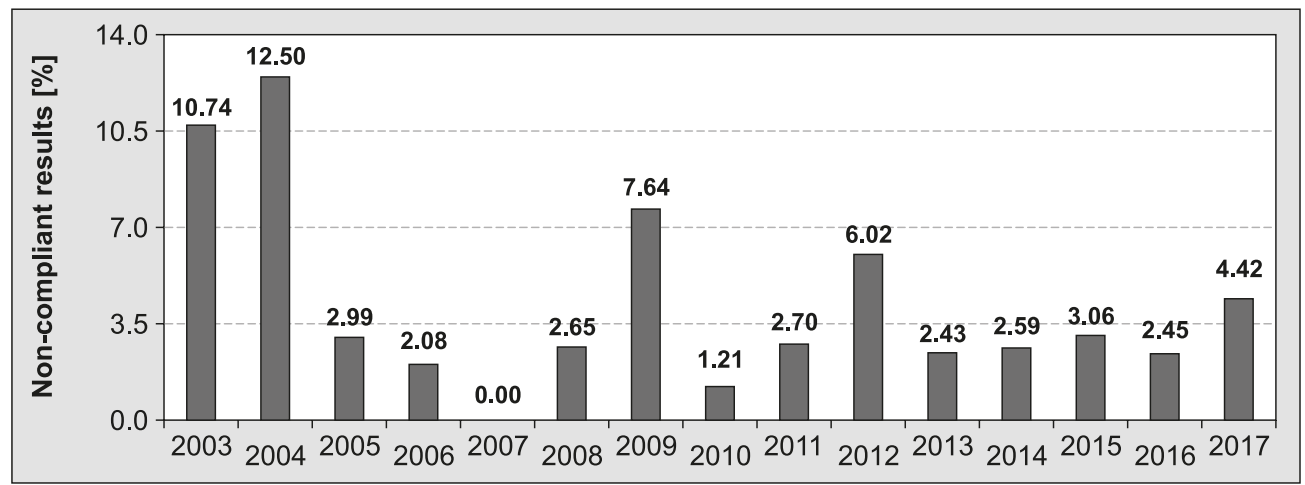

Fig. 4. Percentage of results non-compliant with EU MRLs (Maximum Residue Levels) for antibiotics and chemotherapeutics in honey from 2003 to 2017 showed no deviations from the legal requirements for poultry samples. In 2016, a total of 1180 samples from chickens, turkeys, geese and ducks were tested for antibacterial substances (0 non-compliant results), and 1050 samples for antibiotics and chemotherapeutics (13 non-compliant results for chicken tissue). The majority of the detected compounds were doxycycline, which was found in 11 muscle samples, one of which came from a farm where a misuse of the antibiotic was suspected. In one of the muscle samples containing doxycycline residues, enrofloxacin was detected at the same time. Fifteen samples tested for colistin came from chickens, turkeys and ducks. MRL was not exceeded in any of these samples. Tissues from poultry are also monitored for coccidiostat residues. Salinomycin was detected in 2 liver samples out of 710 samples taken from chickens, which is $0.28 \%$. In the remaining 142 turkey, geese and duck samples, no coccidiostatic drugs were detected.

In 2017, none of the 1471 poultry tissue samples tested for antibacterial substances and none of the 16 samples tested for colistin exceeded MRLs. A total of 1180 tissue samples were tested for antibiotics and chemotherapeutics. Chicken tissues made up nearly $90 \%$ of the samples (1049), 3 of which were noncompliant in terms of doxycycline residues. A total of 872 samples were tested for coccidiostats. Salinomycin and toltrazuril were detected in chicken liver, and halofunginone was present in turkey liver (one positive sample each). Out of the 753 samples tested for chloramphenicol (group A6), one sample of chicken muscle showed the presence of this antibiotic.

Honey. During the 15 years of research, 2587 targeted honey samples were analyzed for residues of antibiotics and antibacterial substances from group B1 (Fig. 4) Among them, 110 non-compliant results were found, which accounts for $4.25 \%$ of all samples tested. Regulations define no MRLs for these drugs in honey, and therefore any amount detected was treated as a non-compliant result. In 2017, 226 samples were tested for antibiotics and antibacterial drugs, but $93.80 \%$ of them (212 out of 226) were tested exclusively for sulfonamides. Sulfonamide residues were found in $4.25 \%$ of the samples (in 9 out of 212). In the remaining 16 studies, streptomycin residues were 
found in one sample. In addition, 76 samples were tested in 2017 for antimicrobial substances that are not allowed in animals (group A6). In one of them, nitrofuran residues were detected.

Milk. From 2003 to 2017, 26,965 milk samples were tested for antibiotic and antimicrobial residues from group B1, and 61 non-compliant results were found. The percentage of non-compliant results

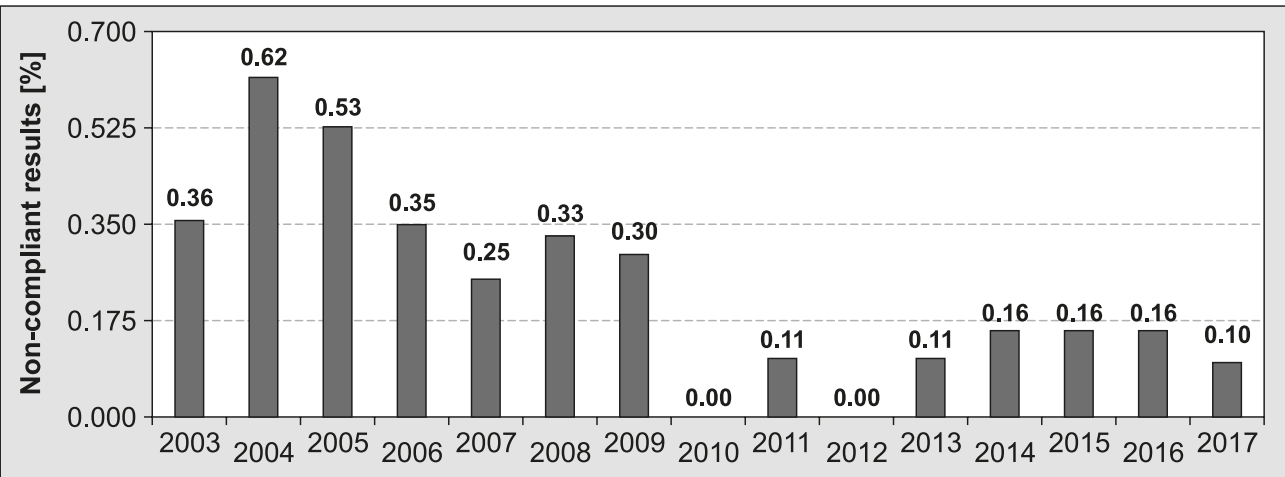

Fig. 5. Percentage of results non-compliant with EU MRLs (Maximum Residue Levels) for antibiotics and chemotherapeutics in milk from 2003 to 2017

did not exceed $0.62 \%$ (2004), and in 2010 and 2012 no antibiotic residues were detected at all. Moreover, in the last 8 years, non-compliant results did not exceed $0.16 \%$ of all samples tested (Fig. 5). The number of samples tested increased by $19.13 \%$ from 2003 . In 2016 and 2017, respectively, 1914 and 1986 samples were taken. In 2016, 3 out of 140 samples tested for antibiotics and chemotherapeutics from group B1 were found positive. Two of them contained tetracycline, and one contained gentamicin. The remaining 1763 samples tested for the presence of antibacterial substances and 11 samples tested for amphenicol complied with the requirements. Moreover, chloramphenicol, belonging to the group of prohibited substances, was found 3 samples, that is, in $1.45 \%$ of all tested for this substance. In 2017, one sample tested for the presence of antibiotics and chemotherapeutics exceeded MRLs for oxytetracycline and tetracycline. Milk samples tested for antibacterial substances (1751 samples) and amphenicols (10 samples) gave results in accordance with the requirements.

Monitoring the presence of residues of unauthorized substances, chemical and biological residues, medicinal products and radioactive contaminants in food is an important component of the system protecting consumers from unsafe food.

Undeniably, the greatest risk associated with the presence of antibiotic residues in tissues from animals intended for human consumption is the potential induction of resistance to the antibiotic itself or its active metabolites in micro-organisms present in the human body. It is believed that the gastrointestinal tract is one of the key sites for the transmission of resistance between animals and humans (9).

The risk of residues in tissues is particularly noticeable in African countries, where access to antibiotics is often widespread, with no veterinary supervision of their use. Inappropriate use of medicines results in exceptionally high prevalence of samples exceeding the maximum permitted levels of drug residues in tissues (27).

Bacterial resistance to antibiotics is becoming an increasingly serious threat to public health worldwide. According to the 2017 EFSA report and independent
Tab. 2. Percentages of non-compliant results in Poland in 2016 and 2017 and the average for the EU countries in 2016

\begin{tabular}{|l|c|c|c|}
\hline \multicolumn{1}{|c|}{$\begin{array}{c}\text { Products } \\
\text { of animal origin }\end{array}$} & \multicolumn{3}{c|}{ Non-compliant results } \\
\hline UE 2016 [\%] & PL 2016 [\%] & PL 2017 [\%] \\
\hline Swttle/beef & 0.15 & 0.24 & 0.24 \\
Poultry & 0.15 & 0.10 & 0.22 \\
Sheep \& goats & 0.18 & 0.58 & 0.11 \\
\hline Equids & 0.32 & 0.00 & 0.00 \\
Milk & 0.80 & 0.00 & 0.00 \\
\hline Eggs & 0.06 & 0.16 & 0.10 \\
Aquaculture & 0.18 & 0.00 & 0.27 \\
\hline Honey & 0.34 & 0.00 & 0.00 \\
\hline
\end{tabular}

studies conducted in various EU countries, antibiotic residues are now the most frequently found group of chemical contaminants in food of animal origin. Continuous monitoring of residues of antibiotics in food is essential. Data from all European countries indicate that MRLs are exceeded most frequently in tissues of equines $(0.8 \%)$ and honey $(0.8 \%)$. According to data on the presence of antibiotic residues in horse meat in Poland between 2003 and 2017, only single non-compliant results were found in 2004, 2007 and 2008. After 2008, no antibiotic residues were detected in horse meat. It should be noted, however, that the slaughter of horses is a small-scale industry in Poland, and the annual number of samples taken usually does not exceed 30.

According to the results of the monitoring studies conducted in Poland, antibiotic residues were most frequently found in honey. This is consistent with the data in the EFSA report on the monitoring of residues of veterinary medicinal products and other substances in food of animal origin in the EU countries (7). There are no antibiotics and chemotherapeutics registered for bees in Poland, but their use is allowed by the ,cascade' system $(4,5)$. Preparations included in the list of authorized substances in Commission Regulation (EU) No 37/2010 may therefore be used for treatment (2). However, the absence of MRLs for these substances in honey means that any amount found is inconsistent 
with EU legislation. Some antibiotics, such as oxytetracycline, tylosin or furazolidone, may degrade in honey or be removed by bees. Most antimicrobials, however, are not actively metabolized by insects, so that residues can be detected in honey harvested one year after administration of the preparation, and its concentration is reduced by progressive dilution with honey produced by bees no longer receiving the antibiotic $(23,24)$.

The results of studies conducted in the EU in 2016 indicate that antibiotic residues in tissues of cattle, pigs and poultry destined for slaughterhouses were at similar levels as in Poland. In the EU, non-compliant results were, on average, slightly less frequent, $0.15 \%$ for tissues from cattle and pigs and $0.18 \%$ for poultry (12). On the other hand, studies in African countries show that MRLs were significantly exceeded in products such as milk, beef and poultry. Tetracyclines $(41.17 \%)$ and $\beta$-lactams $(17.69 \%)$ were among the most commonly used medicinal products there, as well as in Poland. Moreover, a significant percentage of medicines used were chloramphenicol (5.88\%) and nitrofurans $(5.88 \%)$, which are prohibited in the EU (27).

In a survey conducted in Egypt in 2013, 44\% of samples from poultry contained residues of tetracyclines, which exceeded maximum levels in $8 \%, 7 \%$ and $13 \%$ of samples from breast, thigh and liver muscles, respectively (25). In another study in that country, $2 \%$ of 600 samples of bovine tissues analyzed contained residues of oxytetracycline, and $1.2 \%$ were above MRLs (13). In Kenya, $45.6 \%$ of 250 samples tested in 2001 contained residues of tetracyclines: $7.6 \%$ of them were non-compliant muscle samples, $24 \%$ were liver samples and 14\% were kidney samples (14).

In Poland, as well as in other EU countries, antibiotic residues are rarely detected in eggs. In some countries, veterinary medicinal products are also used by people who are not veterinarians, and access to antibiotics is widespread, which, combined with the lack of effective supervision over their use, makes it difficult to determine the real scale of this phenomenon in many parts of the world (27). There are a limited number of antimicrobial medicines authorized for use in laying hens in Poland. In some countries, however, antimicrobial substances are still used in sub-therapeutic doses. Studies carried out in Tanzania indicate that, in 2007, $65 \%$ of small farmers used antibiotics in laying hens without consulting a veterinarian, and the vast majority of them did not know about the withdrawal period and the negative effects of eating food containing residues. Antibiotic residues were found in all 70 samples tested (15). In Nigeria, it has been confirmed that nitrofurans and chloramphenicol, substances which were withdrawn from animal treatment many years ago, are commonly used in poultry $(6,16)$. Studies indicate that antibiotic residues may be present in both egg white and yolk and remain active even after cooking (11).
The problem of administering prohibited substances to food-producing animals clearly persists, as demonstrated by the detection of chloramphenicol residues in tissues and other products. Chloramphenicol has been banned for use in farm animals because of adverse reactions that may occur after consumption of its residues. Studies carried out by Ramos et al. show that chloramphenicol remains highly stable in poultry muscles during prolonged storage under freezing conditions. Other studies also confirm the presence of chloramphenicol in food of plant origin, which indicates the potential for natural occurrence of the antibiotic in the environment due to its illegal use, its use in human medicine and its natural occurrence in Streptomyces fungi (10).

Food of animal origin is an essential part of human diet. Due to the industrial nature of production, antibiotics and other antimicrobial substances are often used to eliminate or prevent the spread of disease in animal herds. However, the results of monitoring studies carried out in Poland indicate that both veterinarians and animal breeders are aware that the proper use of these substances and compliance with withdrawal periods are necessary to ensure food safety. Samples non-compliant with the standards constituted less than $0.3 \%$ of all samples in all types of food. Both in Poland and other European countries, the only exception was honey. This could be effectively remedied by increasing the frequency of controls in apiaries and tests of honey produced there, as well as increasing beekeepers' knowledge of the use of veterinary medicinal products in insects.

\section{References}

1. Beyene T.: Veterinary Drug Residues in Food-animal Products: Its Risk Factors and Potential Effects on Public Health. J. Vet. Sci. Technol. 2016, 7, 285.

2. Commission Regulation (EU) No 37/2010 of 22 December 2009 on pharmacologically active substances and their classification regarding maximum residue limits in foodstuffs of animal origin.

3. Council Directive 96/23/EC of 29 April 1996 on measures to monitor certain substances and residues thereof in live animals and animal products and repealing Directives 85/358/EEC and 86/469/EEC and Decisions 89/187/EEC and $91 / 664 / \mathrm{EEC}$

4. Directive 2001/82/EC of the European Parliament and of the Council of 6 November 2001 on the Community code relating to veterinary medicinal products. (2001). Official Journal of the European Communities, L311, 1-66.

5. Directive 2004/28/EC of the European Parliament and of the Council of 31 March 2004 amending Directive 2001/82/EC on the Community code relating to veterinary medicinal products.

6. Ezenduka E. V., Oboegbulem S. I., Nwanta J. A., Onunkwo J. I.: Prevalence of antimicrobial residues in raw table eggs from farms and retail outlets in Enugu State, Nigeria. Trop. Anim. Health Prod. 2011, 43, 557-559.

7. European Commission: Report on the implementation of national residue monitoring plans in the member states in 2016 (Council Directive 96/23/EC)

8. European Medicines Agency, European Surveillance of Veterinary Antimicrobial Consumption, 2018. 'Sales of veterinary antimicrobial agents in 30 European countries in 2016'. (EMA/275982/2018).

9. Gazzola S., Fontana C., Bassi D., Cocconcelli P. S.: Assessment of tetracycline and erythromycin resistance transfer during sausage fermentation by culturedependent and -independent methods. Food Microbiol. 2012, 30, 348-354.

10. Hanekamp J. C., Frapporti G., Olieman K.: Chloramphenicol, food safety and precautionary thinking in Europe. Env. Liability 2003, 11, 209-221.

11. Khattab W. O., Elderea H. B., Salem E. G., Gomaa N. F.: Transmission of Administered Amoxicillin Drug Residues from Laying Chicken to their Commercial Eggs. Egypt Public Health Assoc. 2010, 85, 297-316. 
12. Lee H. J., Lee M. H., Ruy P. D.: Public health risks: chemical and antibiotic residues. Asian-Aust. J. Anim. Sci. 2001, 14, 402-413.

13. Morshdy A. E., El-Atabany A. I., Hussein M. A., Wageh Sobhy Darwish W. S. Oxytetracycline residues in bovine carcasses slaughtered at Mansoura Abattoir, Egypt. Jpn. J. Vet. Res. 2013, 61, 44-47.

14. Muriuki F. K., Ogara W. O., Njeruh F. M., Mitema E. S.: Tetracycline residue levels in cattle meat from Nairobi slaughterhouse in Kenya. J. Vet. Sci. 2001, 2, 97-101.

15. Nonga H. E., Simon C., Karimuribo E. D., Mdegela R. H.: Assessment of antimicrobial usage and residues in commercial chicken eggs from smallholder poultry keepers in Morogoro municipality, Tanzania. Zoonoses Public Health, 2010, 57, 339-344.

16. Omeiza G. K., Kabir J., Mamman M., Ibrahim H., Fagbamila I. O.: Response of Nigerian farmers to a questionnaire on chloramphenicol application in commercial layers. Vet. Ital. 2012, 48, 87-93.

17. Regulation (EC) No 178/2002 of the European Parliament and of the Council of 28 January 2002 laying down the general principles and requirements of food law, establishing the European Food Safety Authority and laying down procedures in matters of food safety.

18. Regulation (EC) No 470/2009 of the European Parliament and of the Council of 6 May 2009 laying down Community procedures for the establishment of residue limits of pharmacologically active substances in foodstuffs of animal origin, repealing Council Regulation (EEC) No 2377/90 and amending Directive 2001/82/EC of the European Parliament and of the Council and Regulation (EC) No 726/2004 of the European Parliament and of the Council.

19. Regulation of the Minister of Agriculture and Rural Development of 19 Apri 2004 on the manner of handling prohibited substances, chemical and biological residues, medicinal products and radioactive contamination in animals and in products of animal (Dz. U. $2004 \mathrm{nr} 76$ poz. 723).
20. Regulation of the Minister of Agriculture and Rural Development of 20 March 2003 on the control tests of chemical and biological substances, drugs and radioactive contamination in live animals, in tissues or organs of animals after slaughter and in food products of animal products (Dz. U. $2003 \mathrm{nr} 55$ poz. 487).

21. Regulation of the Minister of Agriculture and Rural Development of 21 June, 2017 regarding matters related to prohibited substances, chemical and biological compounds, medicinal products and radioactive contamination.

22. Regulation of the Minister of Agriculture and Rural Development of 28 July 2006 on how to deal with prohibited substances, chemical and biological residues, medicinal products and radioactive contamination in animals and in products of animal origin (Dz. U. $2006 \mathrm{nr} 147$ poz. 1067).

23. Reybroeck $W$ : Residues of antibiotics and chemotherapeutics in honey. J. Apic. Res. 2018, 57, 97-112.

24. Reybroeck W., Daeseleire E., de Brabander H., Herman L.: Antimicrobials in beekeeping. Vet. Microbiol. 2012, 158, 1-11.

25. Salama N. A., Abou-Raya S. H., Shalaby A. R., Emam W. H., Mehaya F. M.: Incidence of tetracycline residues in chicken meat and liver retailed to consumers. Food Addit. Contam. Part B. Surveill. 2011, 4, 88-93.

26. Samanidou V., Nisyriou S.: Multi-residue methods for confirmatory determination of antibiotics in milk. J. Sep. Sci. 2008, 31, 2068-2090.

27. Wageh S. D., Elsaid A. E., Mohamed E., Yoshinori I., Shouta M., Mayumi I.: Antibiotic residues in food: The African scenario. Jpn J. Vet. Res. 2013, 61, Sup.: S 13-22.

Corresponding author: Zbigniew Belkot DVM, PhD, Department of Food Hygiene of Animal Origin, Faculty of Veterinary Medicine, University of Life Sciences in Lublin, ul. Akademicka 12, 20-033 Lublin, Poland; e-mail: zbigniew.belkot@up.lublin.pl 